\title{
Effect of Storage on Physico-Chemical and Sensory Qualities of Commercial Fruit Beverages
}

\author{
Sujata Sethy ${ }^{1 *}$, Kusum Sharma ${ }^{2}$, Asha Dagar ${ }^{2}$ and Renu Mogra ${ }^{2}$ \\ ${ }^{1}$ National Rice Research Institute, Bidyadharpur, Cuttack-753006, Odisha, India \\ ${ }^{2}$ College of Community and Applied Sciences, MPUAT, Udaipur, Rajasthan, India \\ *Corresponding author
}

\begin{tabular}{|l|}
\hline Ke y w o r d s \\
Storage, Fruit beverages, \\
Biochemical analysis, \\
Beta-carotene, Sensory \\
qualities
\end{tabular}

A B S T R A C T
The study was performed to evaluate the effect of storage period on physico-chemical and sensory qualities of commercial fruit beverages. For the study three most popular brands and three least popular brands of fruit beverages i.e. squash and syrup were selected on the basis of market survey and collected within three months of manufacturing date and stored for nine months at room temperature. The samples were subjected to biochemical analysis for acidity, Total Soluble Solid (TSS), total sugar, reducing sugar, $\beta$-carotene, vitamin C, pectin, sodium, potassium and sensory qualities (appearance, colour, flavor and taste) initially and bimonthly interval upto the expiry date. Duration of storage had no effect on the mineral (sodium and potassium) content of the beverages. All the beverages for TSS content satisfied the standards suggested by FPO both for squashes (not less than $40^{\circ}$ brix) and syrup (not less than $65^{\circ}$ brix). Acidity, total sugar, reducing sugar increased with the advancement of storage time while vitamin $C, \beta$-carotene and pectin content of the beverages decreased significantly during storage. Sensory qualities were measured with the help of nine point hedonic scale by panel of ten judges and found that all the beverages were ranged between good and very good initially. A reduction in sensory scores of all the beverages was observed with the advancement of storage period.

\section{Introduction}

Fruits and their value added products belong to an essential class of foods that supply human diet with nutritive requirements including vitamins and minerals which are essential for normal body health and function. They play important roles in the diet of most people in the tropics, providing essential minerals and vitamins and adding colour, flavour and variety to diet (Ragaert et al., 2004). Several reports have shown that adequate intake of fruits and vegetables form an important part of a healthy diet and low fruit and vegetable intake constitute a risk factor for chronic diseases such as cancer, coronary heart disease and cataract formation. In India among the various fruit based beverages, Ready-To-Serve (RTS) beverages ranks first followed by squash and syrup. Squash and syrups are non-alcoholic concentrated beverage that is usually fruitflavoured and made from fruit juice, water and sugar or a sugar substitute. Squash must be mixed with a certain amount of water or carbonated water before drinking. Fruit squash 
and syrups are becoming popular in comparison with synthetic beverages evidently because of their taste, flavour, nutritive value and their storage stability. Fruit squash could be consumed by older infants, children and adults to meet nutrient needs particularly those of micronutrients. They are fat-free, nutrientdense beverages rich in vitamins, minerals and naturally occurring phytonutrients that contribute to good health (Franke et al., 2005). They also promote detoxification in the human body (Deanna and Jeffrey, 2007). Now a days a large number of new brands of fruit juice based beverages have sold in the market, in glass, plastic and Tetra Pack containers.

The stability or shelf-life of a food is defined as the period of time during which it can be stored under certain temperature, humidity, light, etc. conditions, suffering small changes which are considered as acceptable by the manufacturer, the consumer, and the food legislation in force (Moura and Germer, 2010). Several changes may occur in food during processing and storage when it is exposed to different environmental conditions that may trigger a series of reactions, leading to its degradation and consequent rejection by consumers.

Quality changes in fruit-based drinks involve physicochemical, microbiological and sensory changes usually related to heat treatment, chemical composition and initial quality of the drink, oxygen dissolved and present in free space, storage temperature, package and surface of contact, among others (Singh, 2014).

The consumers have several expectations on the foods available in the market including the nutritive value, wholesomeness, purity and safety. This fact is of great importance to the consumer who must know how and for how many days to store the juice containers and when to consume them in order to get the maximum benefit. Hence the present study has been undertaken to evaluate effects of storage on physio-chemical and sensory qualities of commercially available fruit beverages.

\section{Materials and Methods}

A market survey was conducted in the various supermarkets and bakeries of Thrissur district of Kerala, India to prepare a list of fruit beverages available in the market. From the list of fruit beverages three most popular and three least popular brands of beverages were selected for the study. Three different latest batches (samples) (within three months of manufacturing) of each selected beverages were collected and stored for a period of nine months at room temperature $\left(25^{\circ} \mathrm{C}\right.$ to $\left.38^{\circ} \mathrm{C}\right)$.

The samples were subjected to biochemical analysis for TSS, titratable acidity, total sugar, reducing sugar, vitamin-C, beta-carotene, pectin, Sodium and potassium and sensory qualities at bimonthly interval upto the expiry date. Fruit beverages selected for study were categorized as follows:

I. Beverages of most popular brands: i) Orange squash (Squash A), ii) Pineapple squash (Squash B) and iii) Pineapple syrup (Syrup C).

II. Beverages of least popular brands: i) Lemon squash (Squash D), ii) Orange squash (Squash E) and iii) Pineapple syrup (Syrup F).

\section{Physico-chemical analysis}

\section{Total soluble solids $\left({ }^{\circ} \mathbf{B}\right)$}

TSS was determined with the help of hand refractometer of range $0-32^{\circ} \mathrm{B}$, (Model ERMA). The TSS was recorded by placing 12 drops of extract on the prism of a hand refractometer. The results were expressed as ${ }^{\circ}$ Brix (Ranganna, 2007). 


\section{Titratable acidity $(\%)$}

Titratable acidity was estimated by titrating a known volume of the sample against standard $0.1 \mathrm{~N} \mathrm{NaOH}$ solution using phenolphthalein as an indicator up to the end point (pink colour). The titratable acidity was expressed as per cent citric acid (AOAC, 2005).

\section{Total sugar and reducing sugar (\%)}

The content of total sugar and reducing sugar of selected beverages was estimated by using Fehling's solution A and B and methylene blue as an indicator (Ranganna, 2007) and expressed as per cent.

\section{Ascorbic acid (mg/100mL)}

Ascorbic acid content was determined as per AOAC (2005) method using 2, 6dichlorophenol indophenol dye.

A known volume of the sample extracted in 3\% metaphosphoric acid was titrated with dye to pink colour as end point. Results were expressed as mg per $100 \mathrm{~g}$ of sample and calculated by using the following formula:

Ascorbic acid $(\mathrm{mg} / 100 \mathrm{~g})=$ Titre $\times$ Dye factor $\times$ Volume made up/Aliquot of extract taken $\times$ Weight of samplex 100

\section{Beta-carotene $(\mu \mathrm{g} / 100 \mathrm{ml})$}

The estimation of $\beta$-carotene was done by the extraction of $3 \mathrm{ml}$ of sample with acetone and petroleum ether. It was further purified with acetone, methanolic $\mathrm{KOH}$ and distilled water. The resulting solution was filtered with anhydrous sodium sulphate and read on a spectrophotometer at $435.8 \mathrm{~nm}$ against petroleum ether as a blank.

A standard graph was plotted using synthetic crystalline $\beta$-carotene dissolved in petroleum ether and its optical density was measured and expressed as $\mu \mathrm{g}$ of carotene $/ 100 \mathrm{ml}$ (AOAC, 2005).

\section{Sodium and potassium content}

Sodium and potassium content of beverages were estimated by using Flame photometer as suggested by Jackson (1973).

\section{Pectin content}

Pectin substances present in fruit juices were determined as calcium pectate following the method given by Ranganna (2007). $25 \mathrm{ml}$ of fruit juice was precipitated with four volume of acidified alcohol (5ml HCL/lit). The solutions were then centrifuged and the precipitates were washed with $75 \%$ alcohol. The ppt. was then collected, washed, dried and measured gravimetrically. The amount was expressed as percentage.

\section{Sensory properties}

Initially and periodically at bimonthly intervals upto the expiry date, sensory properties of all the fruit beverages were evaluated by a panel of ten judges (Jellinek, 1985). All the panelists were briefed before evaluation. Sensory attributes like appearance, color, flavour and taste for all samples were assessed using nine point hedonic scales. The samples were coded with letters and served to the panelists at random to guard against any bias.

\section{Statistical analysis}

The observations recorded were tabulated and the data was analyzed statistically using Completely Randomized Design (CRD). The significant difference between the batches was assessed using the critical difference (CD) at five per cent level. The scores of organoleptic evaluation were analyzed by Kendall Wallace Analysis of Variance. Statistically, Kendall's coefficient of concordance (w (a)), which 
expresses the degree of association among the ten judges was worked out for each character under study.

\section{Results and Discussion}

All the fruit beverage samples were subjected to physico-chemical and sensory analysis in triplicate initially and were subjected to storage studies at bimonthly interval up to ninth month and the data were presented in table I.

\section{Titratable acidity (\%)}

Initial titratable acidity of fruit beverages ranged from $1.08 \%$ (Syrup F) to $1.60 \%$ (Squash D) The acidity of all different batches of squash and syrup was found to be lower than the acidity of not less than 1.5 per cent suggested by FPO except squash D. Similar finding was observed by Manan et al., (1992) in apricot squash. During the storage period a significant increase in the acidity of beverages was observed in all the beverages except squash B. Jothi et al., (2014) also observed an increase in acidity of mixed fruit squash during storage and the increase in acidity might be due to the interaction of organic acids present in the beverages.

\section{Total soluble solids $\left({ }^{\circ} \mathrm{B}\right)$}

The mean TSS of squash A and B was found to be $50.67^{\circ}$ brix and $40.5^{\circ}$ brix respectively where as in syrup C, the TSS was found to be $75^{\circ}$ brix. In case of least popular beverages the mean TSS of squash D and E was found to be $42^{0}$ and $51^{0}$ brix respectively where as in the case of syrup F, the TSS was found to be $74.33^{0}$ brix during initial period of storage. All the beverages for TSS content satisfied the standards suggested by FPO both for squashes (not less than $40^{\circ}$ brix) and syrup (not less than $65^{\circ}$ brix). The TSS content remained unchanged throughout the storage period for squash A \& D and an increase trend was observed in case of squash B \& E and syrup C $\&$ F, which might be due to hydrolysis of polysaccharides into monosaccharide and oligosaccharides. Rahman et al., (2014) also observed total soluble solids values increase throughout the storage period in different fruit juice concentrate.

\section{Total sugar and reducing sugar (\%)}

Total sugar content of fresh beverages was between $30.79 \%$ and $54.82 \%$, which increased with the advancement of storage. The increase in total sugar was found to be statistically significant in all beverages except squash B and D. Though a faster increase in total sugar was noticed during the initial period of storage, the rate of increase slowed down during third to fifth month of storage in almost all the beverages. Initially, reducing sugar content of 18.94 per cent (squash A), 19.24 per cent (squash B) and 34.20 per cent (syrup C) was observed in case of three most popular beverages where as in case of least popular beverages the reducing sugar content was found to be 16.67 per cent (squash D), 17.36 per cent (squash E) to 35.91 per cent (syrup F). With the advancement of storage period significant increase was observed in all the beverages except squash B. Increase in total sugar content and reducing sugar content during storage was also observed by Dhiman et al., (2017) in pumpkin based squash.

\section{Sodium and potassium content}

The initial sodium content of fruit beverages ranged from $1.12 \mathrm{mg} / 100 \mathrm{ml}$ (syrup C) to 5.56 $\mathrm{mg} / 100 \mathrm{ml}$ (squash A) and potassium content of the beverages ranged from $27 \mathrm{mg} / 100 \mathrm{ml}$ (squash D) to $81.60 \mathrm{mg} / 100 \mathrm{ml}$ (squash A). Storage of the beverages did not affect the mineral content and the finding was supported by Dhaliwal and Hira (2001). 
Int.J.Curr.Microbiol.App.Sci (2018) 7(10): 1138-1147

Table.1 Effect of storage period on physico-chemical and nutritional Constituents of various beverages

\begin{tabular}{|c|c|c|c|c|c|c|c|}
\hline \multirow{2}{*}{$\begin{array}{l}\text { Storage period, } \\
\text { months }\end{array}$} & \multicolumn{7}{|c|}{ Characteristics } \\
\hline & $\begin{array}{c}\text { Acidity } \\
(\%)\end{array}$ & $\begin{array}{l}\text { TSS }(0 \\
\text { brix })\end{array}$ & $\begin{array}{c}\text { Total Sugar } \\
(\%)\end{array}$ & $\begin{array}{l}\text { Reducing } \\
\text { sugar }(\%)\end{array}$ & $\begin{array}{l}\text { Sodium } \\
(\mathbf{m g})\end{array}$ & $\begin{array}{l}\text { Potassium } \\
\quad(\mathrm{mg})\end{array}$ & $\begin{array}{c}\text { Pectin } \\
(\%)\end{array}$ \\
\hline \multicolumn{8}{|l|}{ Squash A } \\
\hline Initial & 1.15 & 50.67 & 32.05 & 18.94 & 5.56 & 81.60 & 0.97 \\
\hline 3 & 1.50 & 50.67 & 33.60 & 19.84 & 5.56 & 81.60 & 0.94 \\
\hline 5 & 1.81 & 50.67 & 34.15 & 21.92 & 5.56 & 81.60 & 0.86 \\
\hline 7 & 2.13 & 50.67 & 35.92 & 24.51 & 5.56 & 81.60 & 0.81 \\
\hline 9 & 2.34 & 50.67 & 37.20 & 24.51 & 5.56 & 81.60 & 0.63 \\
\hline$(\mathrm{CD} 0.05)$ & 0.131 & NS & 0.003 & 0.003 & NS & NS & 0.003 \\
\hline \multicolumn{8}{|l|}{ Squash B } \\
\hline Initial & 1.17 & 40.50 & 31.26 & 19.24 & 2.64 & 31.67 & 0.97 \\
\hline 3 & 1.23 & 40.83 & 32.75 & 19.89 & 2.64 & 31.67 & 0.94 \\
\hline 5 & 1.41 & 41.83 & 34.38 & 20.35 & 2.64 & 31.67 & 0.92 \\
\hline 7 & 1.49 & 42.67 & 35.76 & 21.08 & 2.64 & 31.67 & 0.87 \\
\hline 9 & 1.70 & 42.67 & 36.77 & 21.40 & 2.64 & 31.67 & 0.83 \\
\hline (CD 0.05) & NS & 0.499 & NS & NS & NS & NS & 0.026 \\
\hline \multicolumn{8}{|l|}{ Syrup C } \\
\hline Initial & 1.28 & 75.00 & 52.08 & 34.20 & 1.12 & 58.00 & 0.90 \\
\hline 3 & 1.60 & 75.17 & 53.42 & 35.31 & 1.12 & 58.00 & 0.82 \\
\hline 5 & 1.92 & 75.17 & 54.11 & 35.31 & 1.12 & 58.00 & 0.79 \\
\hline 7 & 1.99 & 75.5 & 55.56 & 36.45 & 1.12 & 58.00 & 0.75 \\
\hline 9 & 2.21 & 75.67 & 61.27 & 41.25 & 1.12 & 58.00 & 0.69 \\
\hline$(\mathrm{CD} 0.05)$ & 0.120 & 0.210 & 0.123 & 0.540 & NS & NS & 0.052 \\
\hline \multicolumn{8}{|l|}{ Squash D } \\
\hline Initial & 1.60 & 42.00 & 30.79 & 16.67 & 3.44 & 27.00 & 1.01 \\
\hline 3 & 1.60 & 42.00 & 31.89 & 17.36 & 3.44 & 27.00 & 0.98 \\
\hline 5 & 1.92 & 42.00 & 32.71 & 19.42 & 3.44 & 27.00 & 0.85 \\
\hline 7 & 2.14 & 42.00 & 33.60 & 21.63 & 3.44 & 27.00 & 0.81 \\
\hline 9 & 2.23 & 42.00 & 34.53 & 22.83 & 3.44 & 27.00 & 0.79 \\
\hline$(\mathrm{CD} 0.05)$ & 0.003 & NS & 0.103 & 1.24 & NS & NS & NS \\
\hline \multicolumn{8}{|l|}{ Squash E } \\
\hline Initial & 1.12 & 51.00 & 35.31 & 17.36 & 3.78 & 41.33 & 0.78 \\
\hline 3 & 1.28 & 52.00 & 35.92 & 18.94 & 3.78 & 41.33 & 0.73 \\
\hline 5 & 1.60 & 52.50 & 36.55 & 21.93 & 3.78 & 41.33 & 0.68 \\
\hline 7 & 2.24 & 52.50 & 37.88 & 23.81 & 3.78 & 41.33 & 0.60 \\
\hline 9 & 2.24 & 53.00 & 38.58 & 23.81 & 3.78 & 41.33 & 0.56 \\
\hline$(\mathrm{CD} 0.05)$ & 0.005 & 0.003 & 0.005 & 0.30 & NS & NS & 0.005 \\
\hline \multicolumn{8}{|l|}{ Syrup F } \\
\hline Initial & 1.08 & 74.33 & 54.82 & 35.91 & 1.60 & 54.00 & 1.00 \\
\hline 3 & 1.28 & 74.67 & 56.31 & 37.20 & 1.60 & 54.00 & 0.94 \\
\hline 5 & 1.60 & 75.67 & 57.13 & 37.20 & 1.60 & 54.00 & 0.93 \\
\hline 7 & 1.92 & 76.33 & 57.13 & 37.20 & 1.60 & 54.00 & 0.88 \\
\hline 9 & 2.22 & 77.33 & 61.27 & 41.25 & 1.60 & 54.00 & 0.80 \\
\hline$(\mathrm{CD} 0.05)$ & 0.003 & 0.841 & 0.003 & 0.003 & NS & NS & 0.102 \\
\hline
\end{tabular}

NS- Non significant 
Int.J.Curr.Microbiol.App.Sci (2018) 7(10): 1138-1147

Table.2 Effect of storage on sensory attributes of various beverages

\begin{tabular}{|c|c|c|c|c|c|c|c|c|}
\hline $\begin{array}{c}\text { Sensory } \\
\text { attributes }\end{array}$ & $\begin{array}{l}\text { Storage } \\
\text { period, } \\
\text { months }\end{array}$ & $\begin{array}{c}\text { Squash } \\
\text { A }\end{array}$ & $\begin{array}{c}\text { Squash } \\
\text { B }\end{array}$ & Syrup C & $\begin{array}{c}\text { Squash } \\
\text { D }\end{array}$ & $\begin{array}{c}\text { Squash } \\
\text { E }\end{array}$ & Syrup F & W (a) \\
\hline \multirow{5}{*}{ Appearance } & Initial & 7.8 & 7.5 & 7.9 & 6.9 & 7 & 5.9 & $0.16 * *$ \\
\hline & 3 & 6.7 & 6.6 & 7.7 & 6.8 & 6.5 & 5.7 & $0.21 * *$ \\
\hline & 5 & 6.7 & 6.6 & 7.0 & 5.9 & 6.0 & 5.6 & $0.14 * *$ \\
\hline & 7 & 6.7 & 6.26 & 6.74 & 5.8 & 5.9 & 4.4 & $0.33^{* *}$ \\
\hline & 9 & 5.8 & 4.8 & 5.5 & 5.5 & 5.6 & 4.0 & $0.18 * *$ \\
\hline \multirow{5}{*}{ Colour } & Initial & 7.8 & 6.8 & 7.6 & 7.2 & 7.2 & 6.6 & $0.83^{\mathrm{NS}}$ \\
\hline & 3 & 6.9 & 6.8 & 7.5 & 7.0 & 6.6 & 5.74 & $0.67^{\mathrm{NS}}$ \\
\hline & 5 & 6.6 & 5.34 & 6.6 & 6.0 & 6.4 & 5.6 & $0.72^{\mathrm{NS}}$ \\
\hline & 7 & 6.5 & 5.1 & 6.5 & 5.1 & 5.0 & 4.5 & $0.11^{* *}$ \\
\hline & 9 & 6.3 & 4.7 & 6.0 & 5.0 & 4.6 & 3.8 & $0.07^{\mathrm{NS}}$ \\
\hline \multirow{5}{*}{ Flavour } & Initial & 7.4 & 6.8 & 7.0 & 6.9 & 6.8 & 7.6 & $0.07^{\mathrm{NS}}$ \\
\hline & 3 & 7.3 & 6.6 & 6.5 & 6.8 & 6.4 & 6.6 & $0.03^{*}$ \\
\hline & 5 & 7.0 & 6.6 & 6.4 & 6.6 & 5.7 & 6.5 & $0.10 * *$ \\
\hline & 7 & 6.0 & 5.3 & 6.0 & 5.7 & 5.5 & 5.5 & $0.12 * *$ \\
\hline & 9 & 5.8 & 4.7 & 6.0 & 4.8 & 5.0 & 5.3 & $0.07^{\mathrm{NS}}$ \\
\hline \multirow{5}{*}{ Taste } & Initial & 6.8 & 5.9 & 7.4 & 7.2 & 6.9 & 6.1 & $0.09 *$ \\
\hline & 3 & 6.7 & 5.8 & 7.3 & 7.0 & 6.6 & 6.0 & $0.04 *$ \\
\hline & 5 & 6.7 & 5.7 & 6.7 & 6.4 & 6.0 & 4.7 & $0.09 *$ \\
\hline & 7 & 5.8 & 5.2 & 6.1 & 6.0 & 5.7 & 4.0 & $0.09 *$ \\
\hline & 9 & 5.8 & 4.6 & 4.8 & 5.5 & 5.4 & 4.0 & $0.11^{* *}$ \\
\hline
\end{tabular}

W (a) Kendall's coefficient of concordance, ** Significant at $1 \%$ level, * Significant at $5 \%$ level, NS - non significant 
Fig.1 Effect of storage on vitamin $\mathrm{C}$ content of the beverages

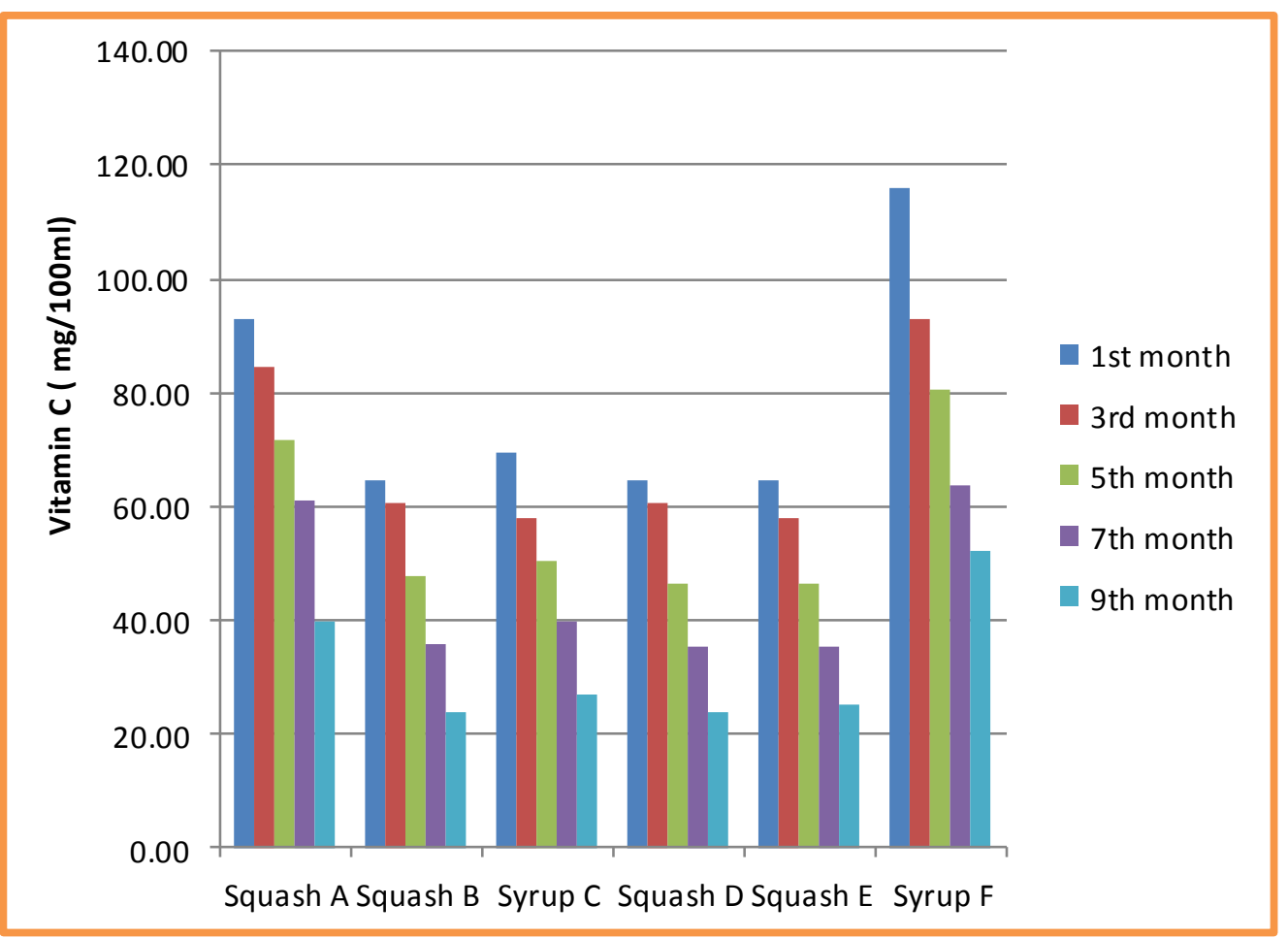

Fig.2 Effect of storage on beta-carotene content of the beverages

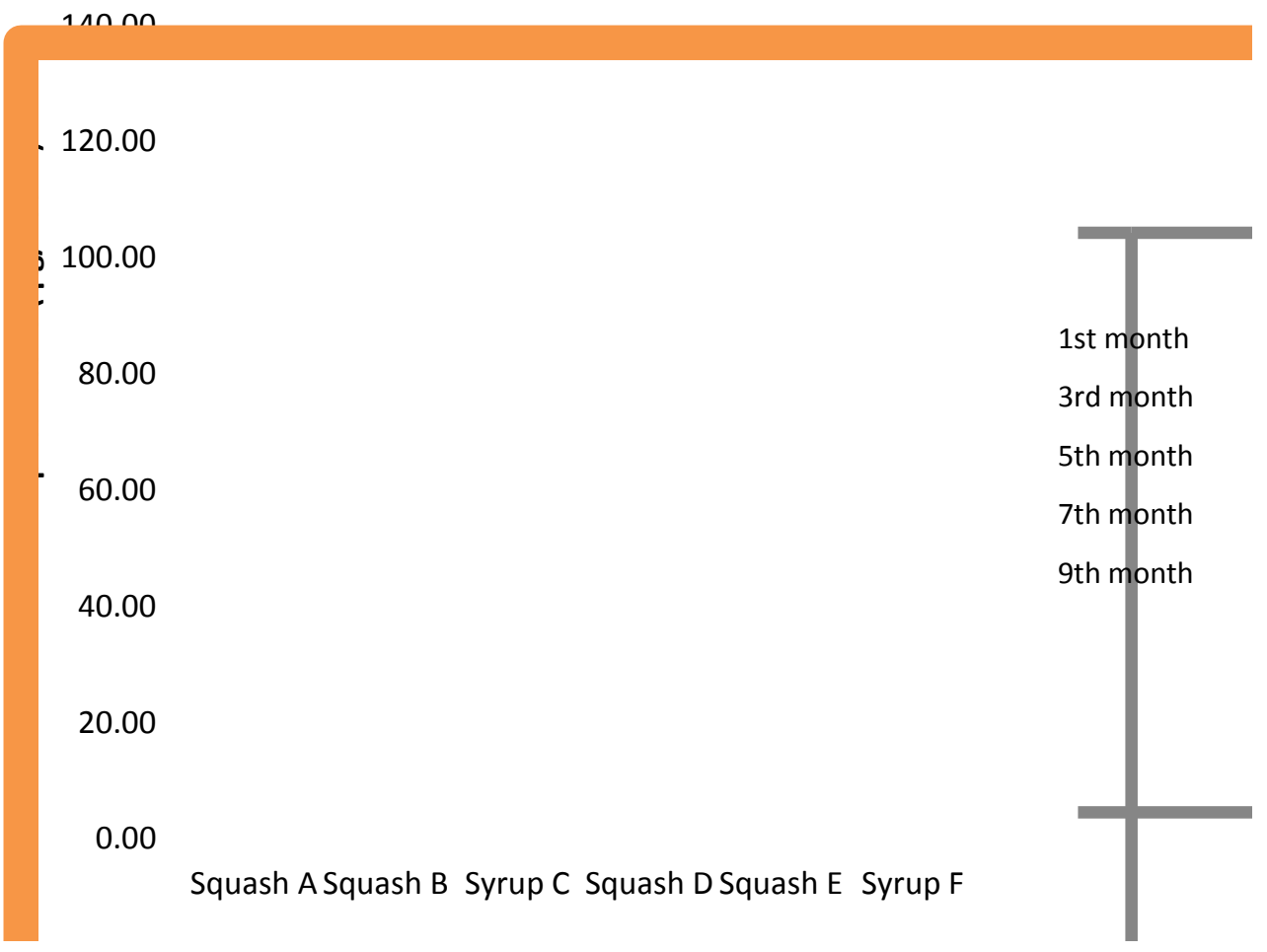




\section{Pectin content}

Initial pectin content of fruit beverages was between $0.78 \%$ in squash $\mathrm{E}$ and $1.01 \%$ in squash D. The pectin content all the beverages, except in squash $\mathrm{D}$ showed significant decrease during storage. In case of squash $\mathrm{A}$ and syrup $\mathrm{F}$ the maximum decrease was observed during the last period of storage

In squash B and $\mathrm{E}$ highest decrease was noted during third phase of study where as in syrup $\mathrm{C}$ and squash $\mathrm{D}$ the highest degradation was during the first and second phases respectively. Mayer and Harel (1960) found that this decrease might be due to conversion of protopectin in to pectinic acid and pectic acid and further to D-galactouronic acid during storage.

\section{Vitamin C (mg/100mL)}

The vitamin $\mathrm{C}$ content ranged from 64.4 $\mathrm{mg} / 100 \mathrm{ml}$ to $116 \mathrm{mg} / 100 \mathrm{ml}$ in the fresh fruit beverages. During storage the vitamin $\mathrm{C}$ content decreased with advancement of time in which a loss of 37.07 percent in squash B and syrup $C$ to 45.09 percent loss in squash $\mathrm{E}$ was observed (Fig. 1). Similar finding of decrease in vitamin $\mathrm{C}$ content was observed by Akubor (2017) in pineapple squash during six month of storage. The decrease in the vitamin $\mathrm{C}$ content of beverages during different months of storage was found to be statistically significant in all brands of beverages except squash $\mathrm{D}$. The vitamin $\mathrm{C}$ content of squash decreased during storage with the progression of storage period, which was probably due to the fact that ascorbic acid being sensitive to oxygen, light and heat was easily oxidized in presence of oxygen by both enzymatic and non-enzymatic catalyst.

\section{Beta-carotene}

Among the different fruit beverages highest beta-carotene was found in squash $\mathrm{E}$
$(115.31 \mu \mathrm{g} / 100 \mathrm{ml})$ followed by squash $\mathrm{A}$ $(112.82 \mu \mathrm{g} / 100 \mathrm{ml})$ and lowest in squash B $\left(89.63 \mu \mathrm{g} 100 \mathrm{ml}^{-1}\right)$. During storage, the betacarotene content decreased in all the beverages. The loss was found to be from 112.82 to $62.55 \mu \mathrm{g} 100 \mathrm{ml}^{-1}$ (squash A), 89.63 to $58.03 \mu \mathrm{g} 100 \mathrm{ml}^{-1}$ (squash B) and 90.09 to $51.00 \mu \mathrm{g} 100 \mathrm{ml}^{-1}$ (syrup C) from first month of storage to ninth month of storage. In case of least popular beverages the decrease was found to be from 98.96 to $62.97 \mu \mathrm{g} 100 \mathrm{ml}^{-1}$ in squash $\mathrm{D}, 115.31$ to $80.20 \mu \mathrm{g} 100 \mathrm{ml}^{-1}$ in squash $\mathrm{E}$ and 99.88 to $55.35 \mu \mathrm{g} 100 \mathrm{ml}^{-1}$ in syrup $\mathrm{F}$ from first month of storage to ninth month of storage (Fig. 2). A significant loss of $\beta$ - carotene has been noticed by Kenghe and Zambare (2009) in bael squash and Dhiman et al., (2017) in Pumpkin-guava squash during storage. A decrease in betacarotene might be due to the auto-oxidative degradation during processing and storage of food (Sharma et al., 2009) or due to oxidative breakdown, isomerization or enzymatic destruction of the pigments.

\section{Sensory qualities}

The effects of storage period on the sensory properties of beverages were shown in Table II. The result revealed that the initial score for appearance was 7.8 (squash A), 7.5 (squash B), 7.9(syrup C), 6.9 (squash D), 7 (squash E) and 5.9 (syrup F). The initial score for colour of beverages ranged from 7.8 in squash A to 6.6 in syrup F. The appearance and colour of the commercial fruit beverages due to some natural pigments present in the fruit and also addition of synthetic food colours like sunset yellow and tartrazine in the fruit beverages (Sethy, 2017).

For flavour the scores obtained highest in syrup F (7.6) though it is a least popular beverage and lowest in squash B and squash $\mathrm{E}$ and the initial score for taste ranged from 7.4 (syrup C) to 5.9 (squash B). With the advancement of storage period there was a 
reduction in the score for appearance and colour in all the beverages which may be due to the deterioration of the pigments. A decreasing trend in the score for flavour and taste was also observed in all the beverages during storage, which may be attributed to the loss of volatile aromatic substances and chemical constituents. Similar findings also observed by Jothi et al., (2014) in mixed fruit squash of papaya, carrot and banana during storage.

On the basis of the results of the study, it may be concluded that all the six fruit beverages irrespective of their popularity can satisfy consumers taste and preference through their nutritional qualities and sensory attributes. These beverages can be stored at room temperature effectively for a period of six months without significant change in physiochemical and nutritional characters and after that a considerable deterioration occurs in all the characters irrespective of beverages. It is also necessary to enforce the existing laws regarding the standards very strictly for the food manufacturers as to maintain the quality standards of food products.

\section{References}

Akubor P. I., 2017. Quality Characteristics and Storage Properties of Squash Prepared from Pineapple (Ananas comosus) Fruit Juice. Asian Journal of Biotechnology and Bioresource Technology. 1(4): 1-8

Association of Official Analytical Chemists (AOAC). 2005. Official methods of analysis. Eighteenth Edition, Association of Official Analytical Chemists, Washington, D. C

Deanna, M. M. and Jeffrey, S. B. (2007). Acid-alkaline balance: role in chronic disease and detoxification. Alternative Therapies. 13(4): 62-65.
Dhaliwal, M. and Hira, C.K. 2001. Effect of storage on physico-chemical and nutritional characteristics of carrotbeetroot and carrot, blackcarrot juices. Journal of Food Science and Technology. 38: 343-347

Dhiman, A. K., NagendraBabu, G., Surekha, A. and Preethi. R. (2017) Development and standardization of ripe pumpkin based squash and its stability during storage. International Journal of Current Microbiology and Applied Sciences. 6(10): 821-831

Franke, A. A., Cooney, R.V., Henning, S. M. and Custer, L. J. (2005). Bioavailability and antioxidant effects of orange juice components in humans. Journal of Agricultural Food Chemistry. 53 (13): 5170-8.

Jackson, M.L. 1973. Soil Chemical Analysis. Prentice hall of India (Pvt.) Ltd., New Delhi, 299 p.

Jellinek, G. 1985. Sensory Evaluation of Food - Theory and Practices. Ellis Horwood Ltd., Chichester, England and VCH Verlagsgerellschaft mbh Weinheim, Federal Republic of Germany, 204 p.

Jothi, J. S., Karmoker, P. and Sarower, K. 2014. Quality assessment of mixed fruit squash: physico-chemical analysis, sensory evaluation and storage studies. Journal of Bangladesh Agricultural University. 12(1): 195-201

Kenghe, R. N. and Zambare, A. V. 2009. Effect of preservation on biochemical qualities of blended bael RTS beverages. Beverage and Food World. 36(4).51-52

Manan, J.K., Kulkarni, S.G. and Shukla, I.C. 1992. Studies on preparation and storage of pulp, squash, nectar and ready to serve beverages from two varieties of apricot (Gola and Chapta) in region of Uttar Pradesh. Beverage Food World. 19:9-12 
Mayer, A.M. and Harel, E. 1960. Polyphenol Oxidises in fruits - Changes during ripening. In: Recent Advances in Biochemistry of fruits and vegetables. (Eds. Friends, J., Rhodes, M.J.C.), Academic Press, 159-178 p.

Moura, S. C. S. R., and Germer, S. P. M. (2010). Reações de transformação e vida-de-prateleira de alimentos processados (Manual Técnico, Vol. 6, 4rd ed., 96 p.). Campinas: ITAL.

Ragaert, P., Verbeke, W. and Debevere, F. 2004. Consumer Perception and Choice of Minimally Processed Vegetables and Packaged Fruits. Journal of Food Quality and Preference 15: 259-270.

Ranganna S. 2007. Handbook of analysis and quality control for fruit and vegetable products. 2nd ed. Tata Mc Graw Hill Publication Co, New Delhi.

Rehman, M. A., Khan, M. R., Sharif, M. K., Ahmad, S. and Shah, Faiz-ul-Hassan. (2014). Study on the storage stability of fruit juice concentrates. Pakistan Journal of Food Sciences. 24(1): 101107

Sethy, S. 2017. Biochemical characterization of fruit juice for impact of storage on commercial beverages. Asian Journal of Dairy and Food Research. 36(4): 316321

Singh, R. P. (2014). Scientific principles of shelf life evaluation. In C. M. D. Man \& A. A. Jones (Eds.), Shelf life evaluation of foods (1st ed., pp. 3-24). London.

\section{How to cite this article:}

Sujata Sethy, Kusum Sharma, Asha Dagar and Renu Mogra. 2018. Effect of Storage on Physico-Chemical and Sensory Qualities of Commercial Fruit Beverages. Int.J.Curr.Microbiol.App.Sci. 7(10): 1138-1147. doi: https://doi.org/10.20546/ijcmas.2018.710.126 